\title{
Metacognitive control over the distribution of retrieval practice with and without feedback and the efficacy of learners' spacing choices
}

\author{
Thomas C. Toppino ${ }^{1} \cdot$ Matthew J. Pagano ${ }^{1}$ \\ Accepted: 15 September 2020 / Published online: 1 October 2020 \\ (C) The Psychonomic Society, Inc. 2020
}

\begin{abstract}
In two experiments on self-regulated learning, participants studied word pairs, made judgments of learning (JOLs), and decided whether to continue practicing after a long or short spacing interval prior to a final cued-recall test. When practice involved restudying, learners preferred a long spacing interval. However, when retrieval practice was involved, learners preferred a short spacing interval for items with low and medium JOLs and a long interval for high-JOL items, regardless of whether retrieval practice was followed by feedback or not. Taking retrieval practice after a short rather than a long spacing interval was efficacious when no feedback followed practice tests, leading to superior recall. Given that retrieval practice was successful, a long spacing interval led to better recall than a short one, but learners were insufficiently accurate in determining which items should be given a long spacing interval for this strategy to be effective. Presenting feedback after retrieval practice did not alter learners' spacing strategy, and the frequent selection of short spacing intervals impaired subsequent recall.
\end{abstract}

Keywords Metacognition · Retrieval practice $\cdot$ Spacing effect $\cdot$ Testing effect

\section{Introduction}

Learning and retention of information improve with repeated practice (Ebbinghaus, 1885/1964). There is a wealth of evidence, however, that memory performance generally improves with increases in the temporal interval separating successive practice opportunities, although performance may decline again if the spacing interval becomes too long (Cepeda, Pashler, Vul, Wixted, \& Rohrer, 2006). This phenomenon is often called the spacing effect or the distributed-practice effect (for a review, see Toppino \& Gerbier, 2014). It occurs both when repetitions involve additional study opportunities (e.g., Madigan, 1969; Melton, 1970) and when they involve tests affording retrieval practice (e.g., Carpenter \& DeLosh, 2005; Modigliani, 1976; Whitten \& Bjork, 1977).

The potent influence of spacing on learning and retention has led to an interest in the degree to which people recognize its effectiveness and in the extent to which they use spacing as

Thomas C. Toppino

thomas.toppino@villanova.edu

1 Department of Psychological and Brain Sciences, Villanova University, 800 Lancaster Avenue, Villanova, PA 19085, USA a metacognitive control strategy in self-regulated learning. Learners seem to have limited awareness of the benefits of spacing, even after they have finished practicing. If learners are asked to predict their later memory performance after engaging in massed or spaced practice, they correctly predict better memory for spaced items when there is a delay between practice and making predictions (e.g., Dunlosky \& Nelson, 1994), but not when predictions are made immediately after practice (e.g., Zechmeister \& Shaughnessy, 1980). This finding may be attributable, in part, to immediate predictions being unduly influenced by transient cues, such as processing fluency, that lead learners to overestimate the benefits of massed practice (Benjamin, Bjork, \& Schwartz, 1998).

Research on the metacognitive-control strategies people use in self-regulated learning has been guided by a conceptual framework in which learners' strategic choices are informed by their assessment of their own current level of knowledge and by their own beliefs or theories about how cognitive processes work (e.g., Nelson and Narens, 1990). Empirical work has addressed two overarching questions: Under what circumstances do learners adopt various strategies, and are learners' strategy choices efficacious in that they enhance later memory performance? A substantial body of research in this area has addressed how and why learners choose some items over others for additional practice (e.g., Ariel, Dunlosky \& 
Bailey, 2009; Dunlosky \& Hertzog, 1997; Metcalfe, 2002; Metcalfe \& Kornell, 2005). However, the research on metacognitive control that is most relevant in the context of the present paper concerns how learners space their practice when they can determine spacing for themselves.

Son (2004) introduced systematic research on how learners use spacing in self-regulated learning. Her participants studied word pairs in anticipation of a final cued-recall test. After studying a pair for $1 \mathrm{~s}$ on its first presentation, they made a judgment of learning (JOL), indicating the likelihood of remembering that item on a later test, and then decided whether to study the pair again immediately (massed practice), later (spaced practice), or not at all. Son found that as JOLs increased, indicating a higher expectation of later recall, the proportion of pairs chosen for massed study decreased while the proportion chosen for spaced study increased. Thus, the relative preference for spaced study compared to massed study increased as JOLs got higher. Son suggested that, when items were poorly processed and poorly learned, participants chose massed practice because they wanted to continue studying. However, to the extent that items were easy or relatively well learned, participants were more likely to choose spaced practice, perhaps believing that immediate continued study would have little beneficial effect.

Subsequent research indicated that Son's results were replicable in conditions in which the study duration for an item's first presentation was short enough that learners could not fully perceive the more difficult (low-JOL) items (e.g., Ariel, Dunlosky, \& Toppino, 2014; Toppino, Cohen, Davis, \& Moors, 2009). However, with a longer initial presentation that ensured perception, learners preferred spaced practice, and the preference was as great or greater for hard, low-JOL items as for easier, higher JOL items (e.g., Ariel et al., 2014; Benjamin \& Bird, 2006; Pyc \& Dunlosky, 2010; Toppino, et al., 2009; Toppino \& Cohen, 2010). Participants behaved as though they prioritized more difficult items and allocated the more effective study strategy (spacing) to those items. Consistent with this view, Toppino and Cohen (2010, Experiment 3) made recalling some items on the final test more valuable by arbitrarily assigning point values to items during the study phase ( 1 vs. 5 points if subsequently recalled) and by instructing participants to prioritize the higher-valued items in order to maximize the number of points achieved on the final test. Results indicated that the preference for spaced practice was markedly greater for high-valued items.

Given that learners' JOL for an item affected the spacing strategy they chose for that item, Son (2010) asked how their spacing choices affected subsequent recall. Adapting a procedure previously used by Kornell and Metcalfe (2006), Son honored learners spacing choices on two-thirds of the trials (e.g., repeating the item immediately when massed practice was chosen) and dishonored them on one-third of the trials (e.g., repeating the item after a relatively long spacing interval even though massed practice had been chosen). Son concluded that spacing was more effective in facilitating subsequent recall when learners had chosen that strategy compared to when it was forced upon them after their choice to "restudy now" was dishonored. She suggested that learners had access to metacognitive knowledge that moderated the spacing effect such that a spacing strategy was more efficacious when learners could choose the items to which it would be applied. However, this conclusion was called into question by Mulligan and Peterson (2014), who noted that the items selected for spaced practice by Son's participants may have been easier than those selected for massed practice. When Mulligan and Peterson controlled item selection artifacts, they found that spacing was equally effective regardless of whether it was the result of an honored or dishonored choice.

In the present paper, we report two experiments extending research on the metacognitive control of spaced practice to conditions in which repetitions involve a practice test (i.e., retrieval practice). We used a variation of Son's (2004) paradigm in which learners studied a pair on its initial presentation, made a JOL, and then decided whether retrieval practice should occur sooner, later, or never (i.e., the Done option). In a slight departure from Son's procedure, when a repetition occurred sooner, it occurred after a lag of two intervening presentations rather than as the very next presentation. This lag was used because it offered a short spacing interval without rendering a practice test trivial (Toppino, LaVan, \& Iaconelli, 2018).

Our interest in the spacing of retrieval practice was prompted, in part, by two recent studies that allowed learners to choose whether to restudy information or to take a practice test (Toppino et al., 2018; Tullis, Fiechter, \& Benjamin, 2018). Results indicated that learners were more likely to choose retrieval practice when items were relatively easy to remember and to choose restudying when items were hard to remember. Toppino et al. also found that learners were more likely to choose retrieval practice when the spacing interval was short (i.e., a lag of two intervening items) rather than long. These findings suggest that learners factor in the likelihood of successful retrieval when they decide to take a practice test or not. Perhaps they believe that a practice test must result in successful retrieval to benefit learning, a view shared by scholars for the case in which retrieval practice is not followed by feedback providing the correct answer (e.g., Kang, McDermott, \& Roediger, 2007; Roediger \& Butler, 2011; Storm, Friedman, Murayama, \& Bjork, 2014). Thus, when repetition involves taking practice tests, learners might exhibit a general preference for a short over a long spacing interval. Also, because a short spacing interval would be especially important to maximize the probability of successful practicetest retrieval for hard items, it seemed possible that the relative preference for a short spacing interval might be greater for hard than for easy items. 
In Experiment 1, we focused on the degree to which participants chose greater or lesser spacing as a function of item JOLs and as a function of whether further practice involved restudying or taking practice tests, with or without feedback. In Experiment 2, we sought to replicate the spacing-choice findings of the previous experiment for conditions in which repetition involved retrieval practice. However, our primary focus was on the degree to which spacing choices were efficacious for final cued recall.

\section{Experiment 1}

As noted earlier, we used a variation of Son's (2004) paradigm in which learners, after studying a pair on its initial presentation, make a JOL and then decide whether the repetition should occur sooner, later, or never (i.e., the Done option). A participant's choice was always honored. Depending on the condition to which learners were assigned, the repeated practice could involve a restudy opportunity, a practice test without feedback, or a practice test with feedback.

We included a restudy condition to maintain a connection to the previous literature. In the event that practice tests yielded a different pattern of results than the well-established pattern obtained with restudying (e.g., Benjamin \& Bird, 2006; Pyc \& Dunlosky, 2010; Toppino \& Cohen, 2010; Toppino, Cohen, Davis, \& Moors, 2009), it was important to know that the critical factor was the use of practice tests and not the use of a short spacing interval in place of immediate massed practice. However, we expected little effect of this procedural variation and predicted that learners generally would prefer to restudy later, with the preference for spaced practice being as large or larger for harder, low-JOL items as for easier, high-JOL items. ${ }^{1}$

In contrast, a different pattern of results seemed likely when repetition involved practice tests that were administered without feedback. As noted earlier, recent research has indicated that learners take into account the likelihood of successful retrieval when deciding to engage in retrieval practice or to restudy information (Toppino et al., 2018; Tullis et al., 2018). If the same principle applies when learners are deciding whether to take a practice test sooner or later, they might be much more likely to choose a short spacing interval than when they are deciding whether to restudy sooner or later. Moreover, a tendency to choose a short spacing interval might be greater for difficult, low-JOL items for which a short

\footnotetext{
${ }^{1}$ A JOL, by definition, is the predicted probability of future retrieval. In the present research, JOLs are construed as an index of the perceived difficulty a participant has learning the item. An item given a low JOL is perceived to be difficult because expecting a low likelihood of future retrieval implies the item was not judged to be well learned on the initial study trial. The opposite would hold for a high-JOL item.
}

spacing interval would be especially important to maximize the probability of successful retrieval practice.

The final condition of Experiment 1 assessed learners' spacing choices when repetitions involved practice tests followed by feedback in which the full pair was presented immediately after recall. One might reasonably expect that learner's spacing choices would differ from those that they make when no feedback is provided. Their pattern of choices might resemble their choices when repetitions involve restudying, because feedback presumably affords a restudy opportunity, regardless of whether retrieval practice is successful.

\section{Method}

\section{Participants}

The sample size was determined on the basis of similar studies previously conducted in our laboratory. A total of 106 undergraduate psychology students volunteered as participants in exchange for class credit. They were assigned randomly to three between-participant conditions that differed in the nature of the repeated practice they received: Restudy, Practice Test with No Feedback, or Practice Test with Feedback. The data of three participants had to be discarded for failure to follow instructions, leaving 34, 35, and 34 participants in the Restudy, Test-No Feedback, and Test-Feedback conditions, respectively.

\section{Materials}

Lists contained 36 word pairs, consisting of common English nouns ranging in length from three to seven letters. The cue and target words in half of the pairs were weakly related, with forward association strengths of .050 to .054 (Nelson, McEvoy, \& Schreiber, 2004), whereas the cues and targets of the remaining pairs had no normative associative connection. We used pairs with different normative within-pair associative relationships to ensure some variability in item difficulty although we were most interested in participants' perception of item difficulty as indicated by their JOLs.

\section{Procedure}

Participants studied a list of 36 word pairs for a later test in which the cue word of each pair was presented and they tried to recall the corresponding target word. The full procedure for their condition was explained, including the list length, and participants received three practice trials to familiarize them with the procedural details associated with the initial study opportunity for each pair. Then, participants studied the word pairs during the experiment's study phase, followed by $5 \mathrm{~min}$ of simple arithmetic problems and the final cued-recall test. 
During the study-phase, the 36 pairs were presented successively in an independent random order for each participant. On an item's first presentation, the full pair was presented for study for $6 \mathrm{~s}$, with the cue word appearing above the target word, separated by a dashed line. Next, participants were asked to make a JOL for that item by choosing one of 11 keys on the top row of the keyboard that had been labeled from 0 to 10 . These numbers corresponded to the probability of recalling the pair, assuming no further study, on a cuedrecall test to be administered $15 \mathrm{~min}$ later. Selecting 0 indicated no chance of recalling the item, whereas 10 indicated a $100 \%$ chance of successful recall. Following the JOL, participants were prompted to decide on whether and when they would practice this pair again, and instructions emphasized that participants' goal in studying should be to maximize recall on the final test. If they chose to practice "sooner," they would practice the pair after two intervening item presentations that could consist of either first or second occurrences of other items. If they chose "later," the item would be presented in a new random order after all items had been presented at least once, following the procedure introduced by Son (2004) and used in subsequent experiments (e.g., Benjamin \& Bird, 2006; Pyc \& Dunlosky, 2010; Toppino et al., 2018). If they chose "Done," they were indicating that no further study was necessary prior to the final test, and a second practice trial was omitted. The Done option was included because of concern that forcing participants to choose practice strategies for items they believed they did not need to practice would result in a systematically different basis of selection, as Son (2004) reported. Thus, without the Done option, we ran the risk of contaminating the primary results of interest which centered on the practice choices participants make when they believe an item would benefit from additional practice.

The second practice opportunity varied with the condition to which participants had been assigned. In the Restudy condition, the second practice opportunity consisted of representation of the full pair for $8 \mathrm{~s}$. In the Test-No Feedback condition, the cue word was presented alone for $8 \mathrm{~s}$, and participants attempted to type in the corresponding target word. In the Test-Feedback condition, the cue alone was presented for $6 \mathrm{~s}$ while participants attempted to type the target word. Then, the full pair (cue plus target) was displayed for $2 \mathrm{~s}$.

In the final cued-recall test, all pairs were tested successively in a new random order. The cue word for each pair was presented for $10 \mathrm{~s}$, during which the participant tried to type the target word for the pair. We carried out the final recall test to fulfill participants' expectations and, to the extent that participants talked among themselves, to confirm the narrative that we were concerned with how their study choices affected their final recall performance. In fact, administering the recall test was not a critical component of Experiment 1. Participants' recall performance was impossible to interpret unambiguously, because it was hopelessly confounded by item selection artifacts. In contrast, Experiment 2 was designed to address how participants' spacing choices affect subsequent recall.

\section{Results and discussion}

\section{Preliminary considerations}

Our primary focus was on how perceived item difficulty and the type of repeated practice (Restudy, Test-Feedback, or Test-No Feedback) affected the proportion of times participants chose to practice again sooner and the proportion of times they chose to practice again later.

Perceived item difficulty was indexed by participants' JOLs. However, whereas there often is wide betweenparticipant variability with respect to the absolute level of JOLs, we were interested in the effect of relative JOLs within participants. Therefore, following precedent in this literature (e.g., Son, 2004, 2010; Toppino et al., 2018), we Vincentized each participant's JOL ratings, effectively normalizing the data. Specifically, each participant's JOL ratings were partitioned into three groups, representing the items given the lowest, medium, and highest ratings, respectively.

To confirm that JOLs reflected the a priori differences in difficulty that were built into the list, JOLs were compared for hard, unassociated pairs $(M=4.006)$ and easy, associated pairs $(M=7.269)$. As expected, easy items yielded significantly higher JOLs, $t(102)=25.164, p<.001, d=2.480$. Also, for every analysis reported below which assessed how spacing choices differed at different levels of JOL, we conducted a parallel analysis substituting a priori item difficulty for JOLs. Results were the same in all cases, so we report only the analyses based on JOLs.

Although the proportion of times that participants chose the Done option (no further practice on a pair) is depicted in the figures displaying the results, it was not included in the data analysis, as our interest was in participants' spacing choices for items that they believed would benefit from further practice. Figures reporting spacing choices in both experiments depict the proportion of Done responses, but these data are not included in the statistical analyses, as our interest was in participants' spacing choices for items they believed would benefit from further practice. The Done option was included specifically so that we could exclude from consideration items that participants did not expect to be affected by further practice. Furthermore, the proportion of times the Done option was selected provides redundant information. Any change in the proportion of items that participants select for further practice corresponds to an opposite change in the proportion of items for which they chose Done.

All statistical analyses employed an alpha level of .05, unless otherwise specified. 


\section{Strategy choice}

The proportions of pairs chosen for further practice were submitted to a $3 \times 2 \times 3$ (JOL $\times$ Choice $\times$ Practice Condition) mixed ANOVA with repeated measures on the first two factors (see Fig. 1). Participants chose to
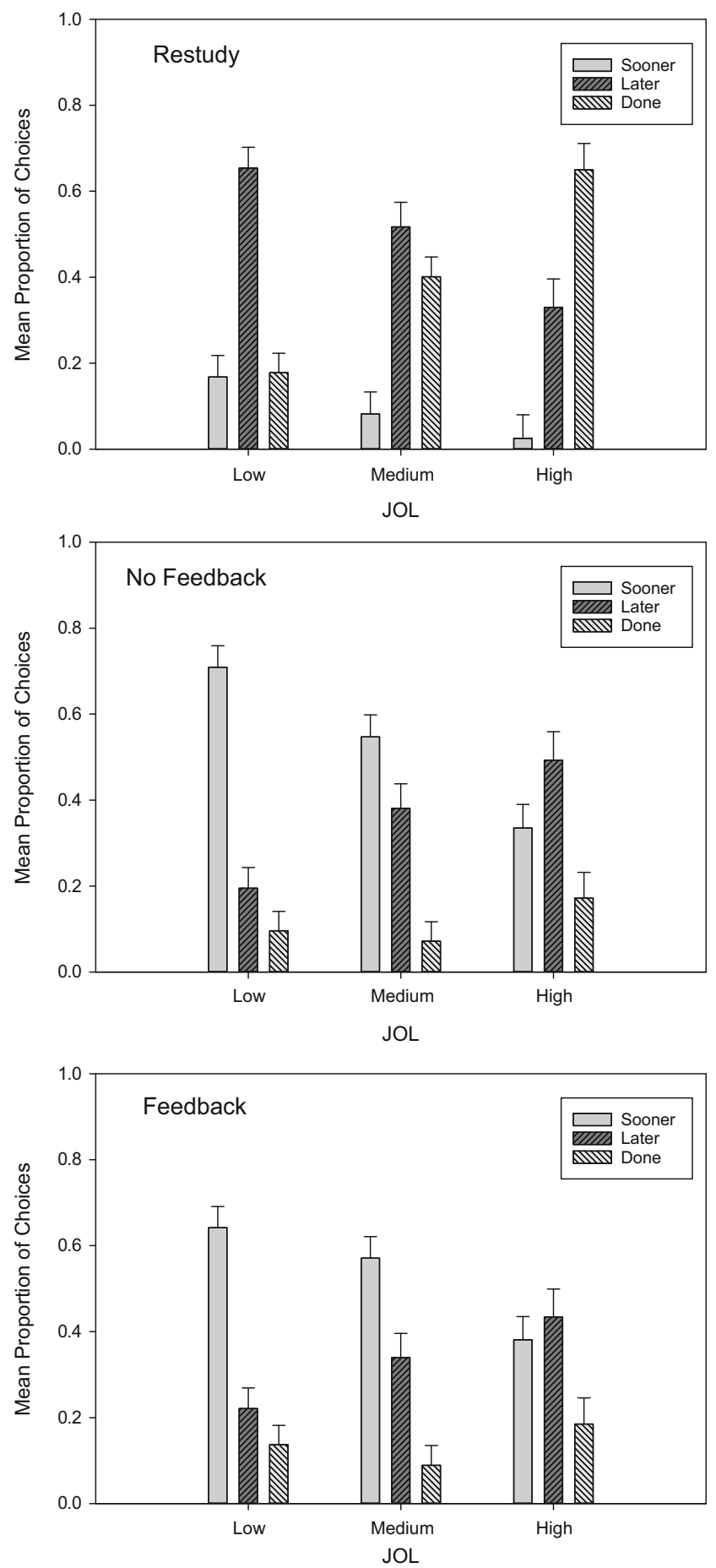

Fig. 1 Mean proportion of choices as a function of judgment of learning (JOL), spacing, and type of practice in Experiment 1. Error bars depict one standard error of the mean practice less (i.e., chose Done more often) as JOL increased, $F(2,200)=21.841, M S E=.025, p<.001, \eta_{\mathrm{p}}^{2}=.179$, and when practice involved restudying compared to retrieval-practice, $F(2,100)=16.110, M S E=.085, p<.001$, $\eta_{\mathrm{p}}^{2}=.244(M \mathrm{~s}=.296, .443$, and .432 , for the Restudy, No Feedback, and Feedback conditions, respectively). The latter difference between conditions was minimal when JOLs were low but was larger for medium and high JOLs, as indicated by a significant JOL $\times$ Condition interaction, $F(4,200)=9.683$, MSE $=.025, p<.001$, $\eta_{p}^{2}=.162$. All other effects were subsumed by a significant JOL $\times$ Choice $\times$ Condition interaction, $F(4$, 200) $=13.498, M S E=.064, p<.001, \eta_{p}^{2}=.213$, which was probed by analyzing the data separately for each practice condition.

As predicted, participants in the Restudy condition generally chose later (spaced practice) over sooner (massed practice), $F(1,33)=55.549, M S E=.153, p<.001, \eta_{\mathrm{p}}^{2}=.627$. The JOL $\times$ Choice interaction was significant, $F(2,66)=3.172$, $M S E=.047, p=.048, \eta_{\mathrm{p}}^{2}=.088$, showing a slight tendency for a greater preference to choose later when items were perceived to be more difficult (low JOLs). However, the preference for greater spacing was evident at all three JOL levels, all $t \mathrm{~s}(33) \geq 4.646, p \mathrm{~s}<.001, d \mathrm{~s} \geq 1.101$.

A different pattern of choices was evident in both retrievalpractice conditions. To determine whether the choice results differed in any way between these two conditions and to explore their shared pattern of results with a more powerful analysis, we conducted a $3 \times 2 \times 2(\mathrm{JOL} \times$ Choice $\times$ Practice-Test Condition) mixed ANOVA with repeated measures on the first two factors. Contrary to the Restudy condition, participants in the retrieval-practice conditions exhibited an overall preference for practicing sooner rather than later, $F(1,67)=8.019, M S E=.451, p=.006, \eta_{\mathrm{p}}^{2}=.107$. There was a significant JOL $\times$ Choice interaction, $F(2$, 134) $=38.972, M S E=.073, p<.001, \eta_{p}^{2}=.368$, such that participants significantly preferred taking practice tests sooner rather than later for low and medium JOLs, $t \mathrm{~s}(68)=7.259, p<.001, d=1.586$, and 2.574 , $p=.012, d=.596$, respectively. However, they preferred to take practice-tests later rather than sooner when JOLs were high. Although the latter difference fell short of significance, $t(68)=-1.264, d=-.278$, it was replicated and was significant in Experiment 2.

Finally, no effect involving the presence or absence of feedback approached significance, all $F \mathrm{~s} \leq 1.305$. The failure of feedback to affect learners' spacing choices may seem surprising, but it is not completely unprecedented. When Kornell and Son (2009) and Toppino et al. (2018) allowed learners to choose whether to restudy or engage in retrieval practice, the presence or absence of feedback following a practice test had little effect on participants' choices in the first of a series of lists. The tendency to choose testing with feedback did 
increase somewhat on later lists, but feedback had no discernable effect on the overall pattern of relative preferences for testing versus restudying. Similarly, post-test feedback did not alter Tullis et al.'s (2018) finding that learners' tend to choose retrieval practice over restudying more for easy than for hard items.

\section{Experiment 2}

One major purpose of Experiment 2 was to assess the replicability of the spacing choices learners make when retrieval practice is involved. Also, we further explored the finding from Experiment 1 that learners' choices were unaffected by whether or not retrieval practice was followed by feedback. In Experiment 1, feedback lasted only $2 \mathrm{~s}$. Learners may have discounted its potential benefit as a study opportunity because of its relatively brief duration. Therefore, in addition to a NoFeedback condition, the present experiment included two Feedback conditions, differing in feedback duration (1 s vs. $4 \mathrm{~s}$ ). Compared to the No-Feedback condition, we expected that $1 \mathrm{~s}$ of feedback would have little effect on learners' spacing choices, replicating Experiment 1. However, participants might be more likely to consider feedback when making their spacing choices when the duration of feedback was extended to $4 \mathrm{~s}$.

A second major purpose of Experiment 2 was to assess the degree to which learners' spacing choices in the practice-test conditions were efficacious in facilitating final cued-recall. Participants in Experiment 1 appeared to be purposeful in their selection of spacing intervals, implying access to information that may direct their choice of an interval for each item. To the extent that learners' choices are based on appropriate information, they should lead to better recall. Therefore, we asked: Is recall better when learners' choice of a short or long spacing interval is granted compared to when the unchosen interval is imposed? To address this question, we used the honor/dishonor paradigm previously used by Kornell and Metcalfe (2006) and applied to the effect of spaced practice by Son (2010) and by Mulligan and Peterson (2014). Most spacing choices were honored by providing a practice test at the chosen time (sooner or later). However, a random minority of choices were dishonored, and the practice test was presented at the time not chosen. Because participants chose the same spacing strategy for both honored and dishonored items, final recall of honored and dishonored items can be compared while avoiding the item selection problems that otherwise would render the recall results uninterpretable. To the extent that learners' choices are efficacious, their final recall should be better following honored as opposed to dishonored choices.

\section{Method}

\section{Participants}

Participants were 138 undergraduate psychology students, with 46 assigned randomly to each of three betweenparticipant conditions differing according to whether practice tests were followed by no feedback, $1 \mathrm{~s}$ of feedback, or $4 \mathrm{~s}$ of feedback.

\section{Materials}

Lists were similar to those used in Experiment 1, except they contained 48 pairs of common English nouns. Again, words within half the pairs had a weak associative relationship, whereas words within the remaining pairs had no normative associative relationship (Nelson et al., 2004).

\section{Procedure}

The procedure was identical to that of Experiment 1, with these exceptions. Participants were instructed that their choice to take a practice test sooner or later would be honored most of the time but that, on a relatively small proportion of trials, their choice would be dishonored and the practice test would be presented at the opposite time. Their choices were honored on two-thirds of the trials and dishonored on a random onethird of the trials in which the unchosen spacing interval was substituted. All done choices were honored. Following the experiment's study-phase, participants engaged in 4 min of simple arithmetic problems before taking the final cuedrecall test on all 48 pairs.

\section{Results and discussion}

\section{Preliminary considerations}

Although all participants contributed usable data for the spacing-choice analyses, not all contributed usable data for the main recall analysis which was performed on recall in the four within-participant conditions defined by the combinations of two spacing choices (sooner vs. later) crossed with two honor-status conditions (honor versus dishonor). The spacing choices of some participants were skewed sufficiently that they did not contribute data to one or more of these four cells. These "empty-cell" participants were excluded from the recall analyses, leaving 36, 38, and 38 participants in the NoFeedback, 1-s Feedback, and 4-s Feedback conditions, respectively.

We separately analyzed the spacing choice data for all participants and for only those who contributed to the recall analysis. The pattern of significant effects was identical, reassuring us that the recall data were not taken from an 
atypical subsample. Therefore, we report only choice results from the full sample.

As in Experiment 1, hard, unassociated pairs yielded lower JOLs $(M=3.634)$ than easy, associated pairs $(M=6.973)$, $t(137)=35.056, p<.001, d=2.985$. Again, we analyzed the choice results twice, in terms of JOLs and then a priori difficulty. Because no differences were observed, we report below only the analyses based on JOLs.

\section{Spacing choice}

The proportions of pairs chosen for further practice were submitted to a $3 \times 2 \times 3(\mathrm{JOL} \times$ Choice $\times$ Feedback Condition) mixed ANOVA with repeated measures on the first two factors (see Fig. 2). The proportion of pairs selected for further practice declined steadily as JOLs increased, $F(2,270)=$ 44.149, MSE $=.013, p<.001, \eta_{\mathrm{p}}^{2}=.246$, indicating that participants chose the done option more frequently when JOLs were higher. Participants also exhibited an overall preference to take practice tests sooner rather than later, $F(1$, $135)=12.340, M S E=.379, p=.001, \eta_{\mathrm{p}}^{2}=.084$. The JOL $\times$ Choice interaction was significant, $F(2,270)=104.090$, $M S E=.082, p<.001, \eta_{\mathrm{p}}^{2}=.435$, but neither the main effect of feedback condition nor any of its interactions attained significance, all $F \mathrm{~s} \leq 1.059$. Probing the JOL $\times$ Choice interaction revealed that we replicated the retrieval-practice findings of Experiment 1. Learners preferred taking the practice test sooner rather than later for low and medium JOLs, $t \mathrm{~s}(137)=$ $11.028, p<.001, d=1.852$, and $2.367, p=.019, d=.396$, respectively. When JOLs were high, however, taking a practice test later was preferred to sooner, $t(137)=-3.555$, $p<.001, d=-.549$.

\section{Recall}

Practice test performance Correct recall on the practice test by the subsample described earlier was analyzed using a $2 \times 2 \times 3$ (Choice $\times$ Honor Status $\times$ Feedback Condition) ANOVA with repeated measures on the first two factors. There were no significant differences associated with Feedback Condition, all $F_{\mathrm{S}}(2,109) \leq 1.387$. However, a significant Choice $\times$ Honor Status interaction was obtained, $F(1,109)=211.530$, $M S E=.027, p<.001, \eta_{\mathrm{p}}^{2}=.660$. When participants' choice to take a practice test sooner was honored, the proportion of correct recall on the practice test $(M=.733)$ was significantly higher than when it was dishonored and they were forced to take the practice test later $(M=.442), t(111)=12.906$, $p<.001, d=1.305$. When they chose to take the practice test later, their proportion of correct recall was higher when their choice was dishonored, forcing them to take the test sooner $(M=.833)$ rather than later $(M=.671), t(111)=-8.069$, $p<.001, d=-.700$. Thus, practice test performance was better when the test was administered sooner, regardless of participants' choices, and regardless of Feedback Condition. Comparisons involving items that participants chose to test sooner versus later are uninterpretable because spacing and item difficulty are confounded as a result of participants opting for a practice test sooner when items were perceived to be difficult and later when they were perceived to be easy.
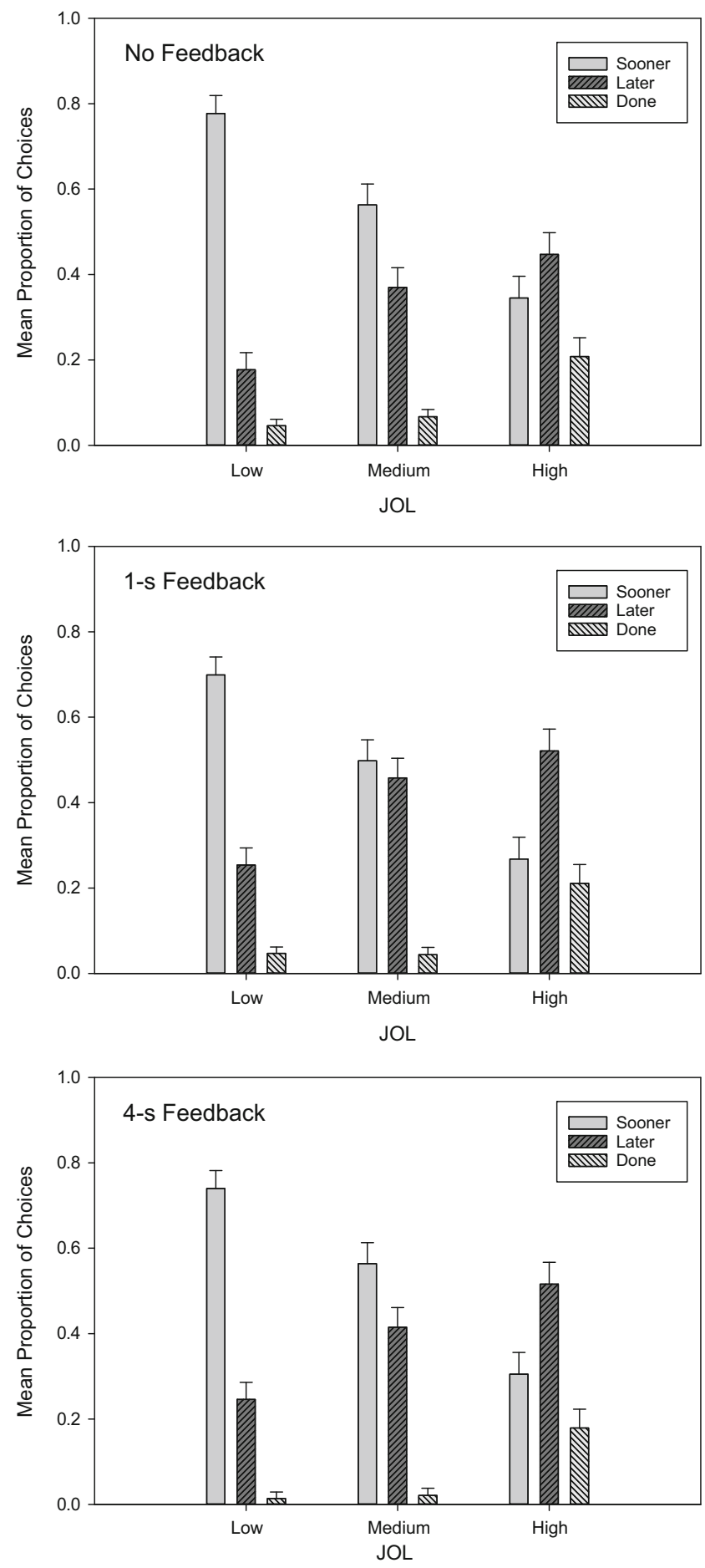

Fig. 2 Mean proportion of choices as a function of judgment of learning (JOL), spacing, and type of practice in Experiment 2. Error bars depict one standard error of the mean 
Final cued-recall performance The mean proportion of correct recall was analyzed by a $2 \times 2 \times 3$ (Choice $\times$ Honor Status $\times$ Feedback Condition) mixed ANOVA with repeated measures on the first two factors. There was a main effect of Feedback Condition, $F(2,109)=7.602, M S E=.124, p=.001$, $\eta_{\mathrm{p}}^{2}=.122$. The overall mean proportion correctly recalled in the 4-s Feedback Condition $(M=.774)$ was higher than in both the No-Feedback Condition $(M=.617)$ and the $1-\mathrm{s}$ Feedback Conditions $(M=.678), t(72)=3.958, p<.001$, $d=.466$, and $t(74)=2.774, p=.007, d=.321$, respectively. However, overall recall in the latter two conditions did not differ significantly, $t(72)=1.307, d=.154$. There also were main effects of Spacing Choice, $F(1,109)=$ 125.335, MSE = .042, $p<.001, \eta_{\mathrm{p}}^{2}=.535$, and Honor Status, $F(1,109)=5.848, M S E=.030, p=.017$, $\eta_{\mathrm{p}}^{2}=.051$, which were qualified by a significant three-way interaction, $F(2,109)=20.233, M S E=.025, p<.001$, $\eta_{\mathrm{p}}^{2}=.271$.

The interaction depicted in Fig. 3 was probed by means of separate $2 \times 2$ (Choice $\times$ Honor Status) repeated-measures ANOVAs for the different Feedback Conditions. For the No-Feedback Condition, the Choice $\times$ Honor Status interaction was significant, $F(1,35)=9.697, M S E=.024, p=.004$, $\eta_{\mathrm{p}}^{2}=.217$. Final recall was better when participants chose to take the practice test sooner and their choice was honored compared to when their choice was dishonored, forcing them to take the practice test later, $t(35)=2.092, p=.043, d=.327$. However, when participants chose to take the practice test later, final recall was significantly better when their choices were dishonored, forcing them to take the practice test sooner rather than later, $t(35)=-2.041, p=.049, d=-.272$. Separate analyses for the 1-s and 4-s Feedback conditions yielded identical patterns of results. Therefore, we included both feedback conditions in a $2 \times 2 \times 2$ (Choice $\times$ Honor Status $\times$ Feedback Condition) ANOVA with repeated measures on the first two factors. The Choice $\times$ Honor-Status interaction was significant, $F(1,74)=44.896, M S E=.025, p<.001, \eta_{\mathrm{p}}^{2}=.378$, but, in contrast with the No-Feedback Condition, recall was better when practice tests were taken later, regardless of whether this resulted from sooner choices being dishonored, $t(75)=-5.916, p<.001, d=-.769$, or from later choices being honored, $t(75)=2.770, p=.007, d=.352$. Also, the main effect of feedback on final recall was significant, $F(1,74)=7.695, M S E=.092, p<.007$, $\eta_{\mathrm{p}}^{2}=.094$, such that recall was higher when feedback lasted for $4 \mathrm{~s}$ instead of $1 \mathrm{~s}$, but none of the interactions involving feedback duration approached significance, all $F_{\mathrm{s}}(1,74) \leq 1.716$.

Finally, all done choices were honored so that participants took the final test after having only studied these pairs one time. Participants recalled these items well $(M=.728)$, which may not be surprising in light of the fact that participants were much more likely to choose to be done with a pair if they perceived it to be easy and expected to be able to recall it with no further practice.

Final cued-recall conditionalized on practice-test performance To explore how final recall was influenced by practice test performance, we analyzed final cued recall as a function
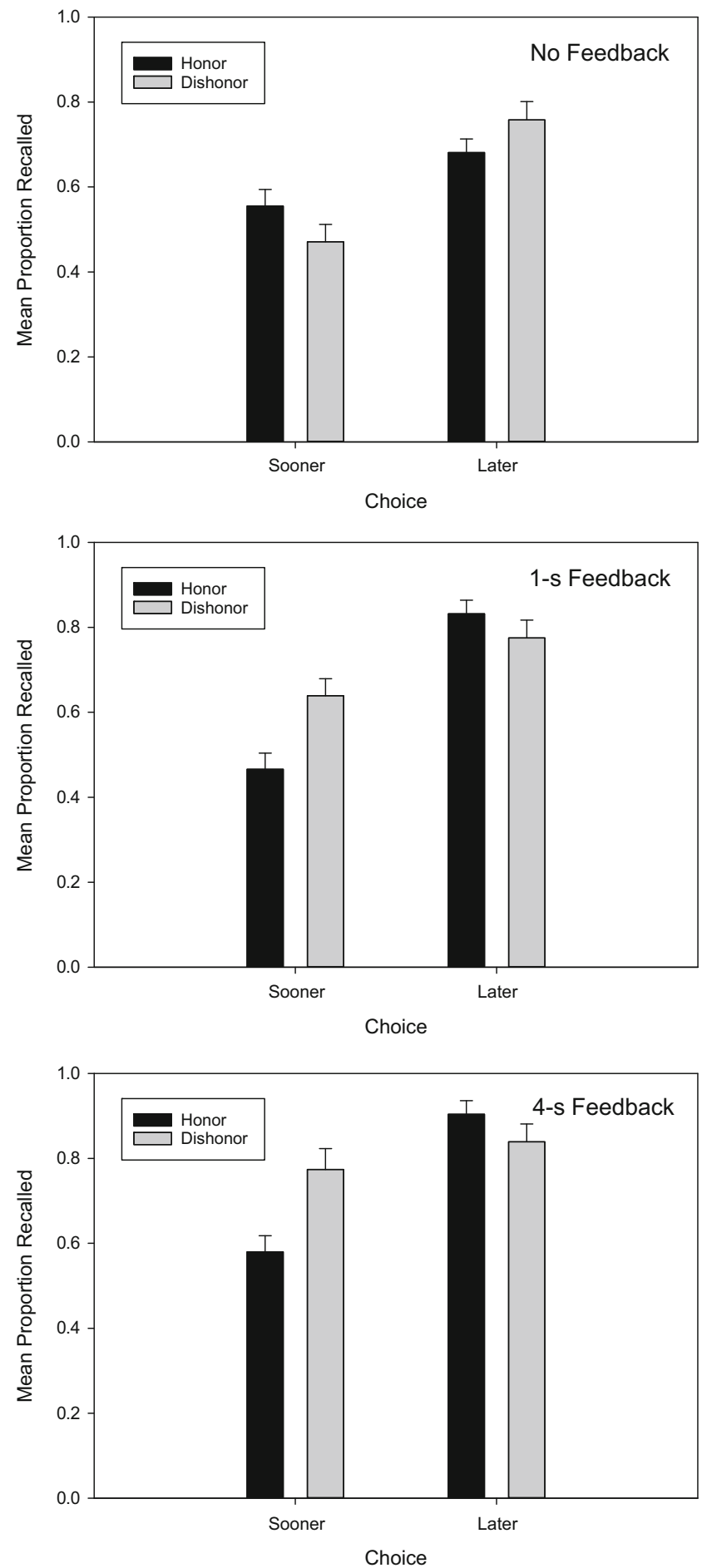

Fig. 3 Mean proportion of correct final recall as a function of choice and whether those choices were honored or dishonored. Error bars depict one standard error of the mean 
of spacing choice and honor status for items that were and were not recalled correctly on the practice test. Some participants had to be excluded from these analyses for failure to contribute any data to one or more of the four within-participant cells of the Choice $\times$ Honor Status design, and the number remaining in the subsample varied with whether practice test performance had been successful or unsuccessful. ${ }^{2}$

Analyses of final recall for items that were recalled successfully on the practice test were based on 30,35 , and 34 participants in the No-Feedback, 1-s Feedback, and 4-s Feedback conditions, respectively. The primary result of a $2 \times 2 \times 3$ (Choice $\times$ Honor Status $\times$ Feedback Condition) mixed ANOVA with repeated measures on the first two factors was a significant Choice $\times$ Honor Status interaction, $F(1,96)=$ $160.051, M S E=.026, p<.001, \eta_{\mathrm{p}}^{2}=.625$, which was not qualified by any interaction involving Feedback Condition, all $F_{\mathrm{s}}(2,96) \leq 2.004$. This interaction is depicted in Fig. 4. Recall was better when a sooner choice was dishonored rather than honored, $t(98)=-13.929, p<.001, d=-2.026$, and when a later choice was honored rather than dishonored, $t(98)=$ $4.651, p<.001, d=.672$. Thus, given that practice-test recall was correct, final recall was better following a long than a short spacing interval, regardless of honor status. Finally, there also was a relatively weak main effect of Feedback Condition, $F(2,96)=3.732, M S E=.027, p<$ $.027, \eta_{\mathrm{p}}^{2}=.072$, which was attributable to somewhat lower overall performance in the 1-s Feedback condition compared to the other conditions. However, there is no obvious explanation for this finding. It seems likely to be an anomaly.

When final recall was analyzed for items that were not recalled successfully on the practice test, the number of participants who could contribute data dropped markedly to 19 , 15 , and 16 participants in the No-Feedback, 1-s Feedback, and 4-s Feedback conditions, respectively. The critical results of a $2 \times 2 \times 3$ (Choice $\times$ Honor Status $\times$ Feedback Condition) mixed ANOVA with repeated measures on the first two factors were a main effect of feedback condition, $F(2,47)=$ 13.510, MSE $=.139, p<.001, \eta_{\mathrm{p}}^{2}=.365$, and a three-way interaction, $F(2,47)=12.837, M S E=.060, p<.001$, $\eta_{\mathrm{p}}^{2}=.353$ (see Fig. 5).

Regarding the main effect of Feedback Condition, the overall mean proportion of final recall for items that were not recalled on the practice test was poorer in the NoFeedback condition $(M=.155)$ than in the 1 -s Feedback condition $(M=.293), t(32)=2.202, p=.035, d=.391$, which was poorer still than in the 4-s Feedback condition $(M=.483)$,

\footnotetext{
${ }^{2}$ Participants who failed all practice tests in one or more of the withinparticipant cells could contribute no data to an analysis of final recall for items that were answered correctly on the practice test. Similarly, participants who were successful on all practice tests in one or more within-participant cells could not contribute data to an analysis of final recall for items that were not answered correctly on the practice test.
}

$t(29)=2.723, p=.011, d=.505$. The three-way interaction was probed by means of separate Choice $\times$ Honor Status repeated-measures ANOVAS for each feedback condition. The Choice by Honor Status interaction was not significant for the No-Feedback condition, $F(1,18)=2.842, M S E=.063$, $\eta_{\mathrm{p}}^{2}=.136$, but was significant for the 1-s and 4-s Feedback conditions, $F(1,14)=10.487, M S E=.047, p=.006$, $\eta_{\mathrm{p}}^{2}=.428$ and $F(1,15)=22.822$, MSE $=.068, p<.001$, $\eta_{\mathrm{p}}^{2}=.603$, respectively. Final recall was better when sooner choices were dishonored in both the 1-s and 4-s Feedback conditions, $t(14)=-2.099, p=.054, d=-.943$, and $t(15)=-$ $3.164, p=.006, d=-1.189$, respectively. Also, final recall was better when later choices were honored in both the 1-s and 4-s conditions, $t(14)=2.172, p=.048, d=.565$, and $t(15)=$ $2.224, p=.042, d=.831$, respectively.

\section{General discussion}

In Experiment 1, we compared learners' spacing choices when the second practice opportunity involved restudying and when it involved practice tests that were or were not followed by feedback. In the restudy condition, participants manifested an overall preference for restudying after longer rather than shorter spacing intervals, and this preference was at least as strong for items that were perceived to be difficult as for those that were perceived to be relatively easy. These results were similar to those of previous research in which participants' ability to fully perceive the item was not in question, despite our use of a different short spacing interval (e.g., Ariel et al., 2014; Benjamin \& Bird, 2006; Pyc \& Dunlosky, 2010; Toppino, et al., 2009; Toppino \& Cohen, 2010). Our findings are consistent with the hypothesis that, when additional practice involves restudying, learners have some awareness that

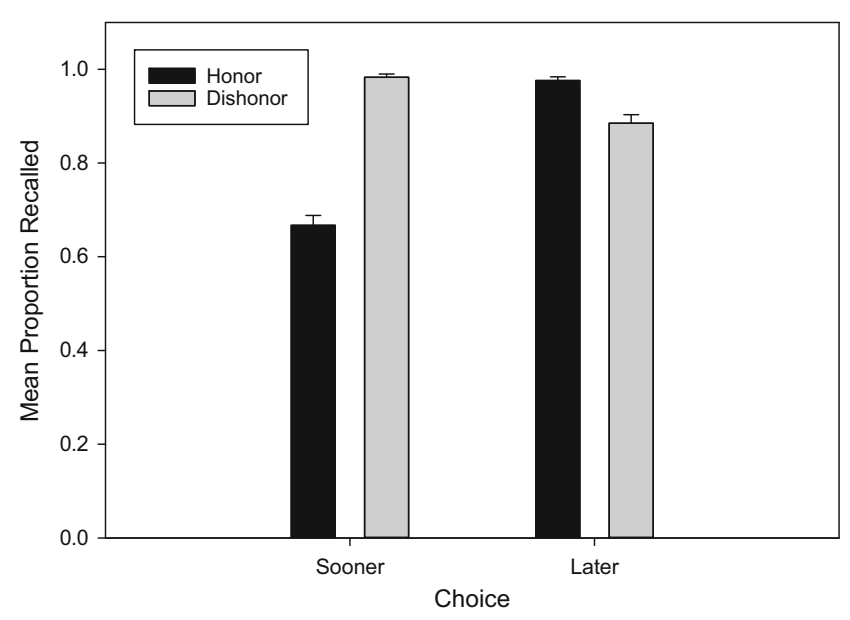

Fig. 4 Mean proportion of correct final recall conditionalized on correct practice-test recall. The data are shown as a function of choice and whether those choices were honored or dishonored on the practice test. Error bars depict one standard error of the mean 
future recall will be better served by practice involving a long rather than a short degree of spacing (e.g., Ariel et al., 2014; Toppino \& Cohen, 2010; Toppino et al., 2009).

In contrast to the Restudy condition, participants in the retrieval-practice conditions of both experiments were more
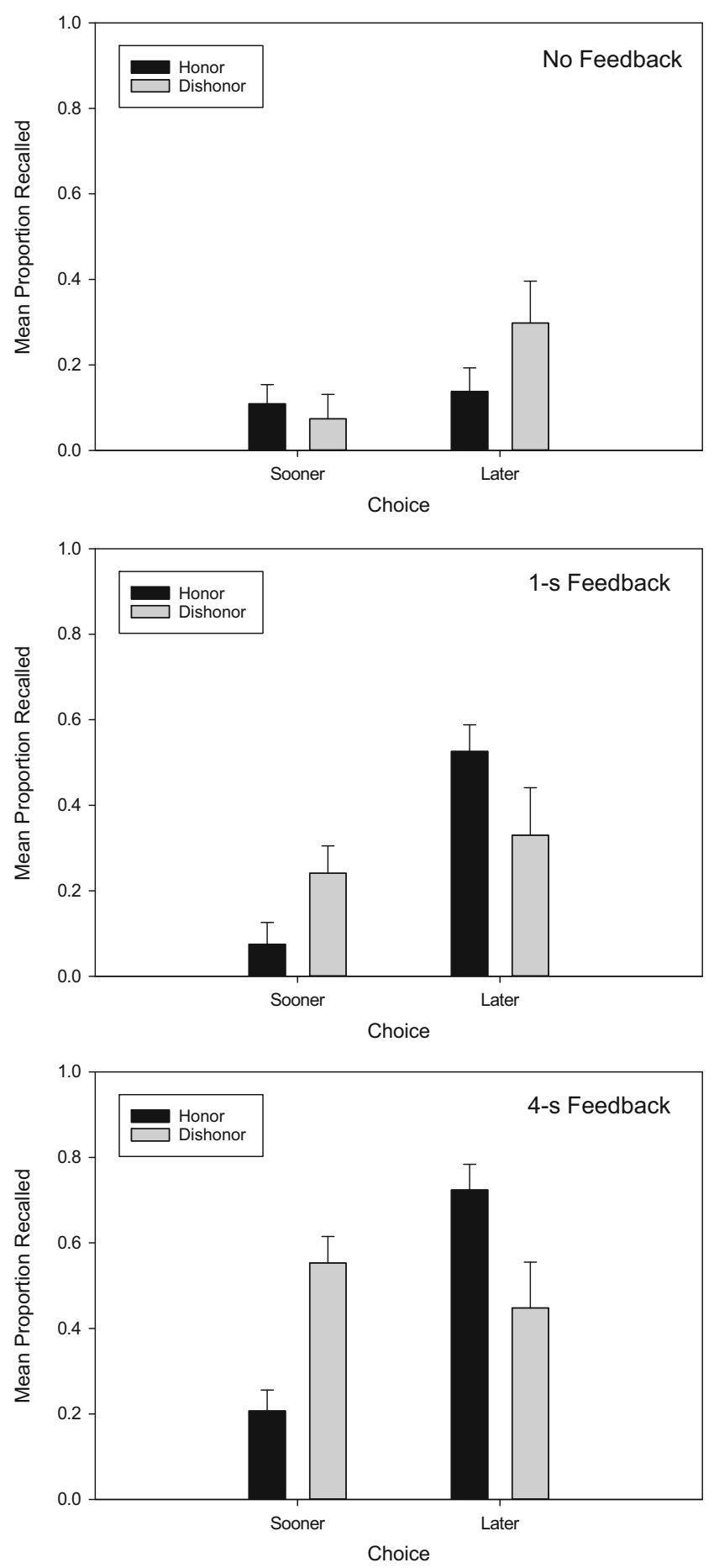

Fig. 5 Mean proportion of correct final recall conditionalized on incorrect practice-test recall. The data are shown as a function of choice and whether those choices were honored or dishonored on the practice test. Error bars depict one standard error of the mean likely to engage in further practice (i.e., less likely to choose the Done option), especially for items they perceived to be medium or easy in difficulty, and they exhibited a different pattern of spacing choices when they did opt for additional practice. As the perceived difficulty of items changed from hard to easy, the tendency to choose a short spacing interval declined, while the propensity to choose a long spacing interval increased. Thus, a short spacing interval was preferred for the hardest items and to a lesser extent for items that were perceived to be of intermediate difficulty. A long spacing interval, however, was preferred for the easiest items. This pattern of choices was obtained regardless of the presence or absence of feedback or its duration.

Learners clearly made metacognitive choices in a systematic manner, suggesting that they may have access to information about items and situations that guides them in determining whether a short or a long spacing interval will be more beneficial for a particular item in a particular situation. Therefore, in Experiment 2, we examined the efficacy of these choices for recall performance. We asked if it made a difference for final recall whether learners' choice of short or long spacing intervals was honored as compared to situations when the same choice was dishonored by using the opposite spacing interval. To better understand learners' strategies and their efficacy, it is useful to examine the No-Feedback and Feedback conditions separately.

In the No-Feedback condition, learners often preferred to take retrieval practice sooner rather than later, especially for items perceived to be difficult. When this choice was honored, practice-test recall was higher, and final recall was better than when it was dishonored. This strategy suggests that learners realize that successful retrieval practice is more likely after a short than a long spacing interval and that they believe that successful retrieval on a practice test is necessary if it is to benefit later recall. This interpretation converges with conclusions from recent research investigating metacognitive control over whether to restudy an item or engage in retrieval practice (Toppino et al., 2018; Tullis et al., 2018). In both papers, learners were more likely to choose retrieval practice over restudying when conditions were conducive to successful retrieval on a practice test. Thus, they were more likely to choose practice tests when items were perceived to be easy to remember (Toppino et al., 2018; Tullis et al., 2018) and when the experimenter-imposed spacing interval was short (Toppino et al., 2018). Tullis et al. (2018) also found that final recall was superior when learners' choice to take retrieval practice rather than to restudy was honored as compared to when it was dishonored, forcing them to restudy.

Learners did not try to maximize retrieval-practice performance by always taking practice tests after a short spacing interval. They opted for a long spacing interval on a minority of items. Because these items mostly were perceived to be relatively easy, it seems likely that learners expected to recall 
them on the practice test despite the long spacing interval. This would be consistent with our earlier conclusion that learners realized that a practice test without feedback would benefit learning only if it enabled successful retrieval. However, learners were overly optimistic. When the choice of a long spacing interval was honored, practice-test performance and final recall were poorer than when the choice was dishonored in favor of a short spacing interval.

Although opting for a long spacing interval did not yield an overall advantage for learners in the present task, it is not necessarily an ill-conceived strategy. Given successful recall on the practice test, final recall was better for items tested after a long than a short spacing interval, regardless of whether choices had been honored or dishonored. This result is consistent with previous findings that final recall increases as a function of increased spacing between original studying and a successful practice test (e.g., Modigliani, 1976; Whitten \& Bjork, 1977). Learners in the present experiments apparently understood the importance of retrieval practice being successful and still chose a longer spacing interval for some items. This implies that they may have some appreciation of the benefits of a longer spacing interval for items that are retrieved successfully on practice tests as well as for items that are restudied, as suggested by the results of Experiment 1 and prior research (e.g., Ariel et al., 2014; Benjamin \& Bird, 2006; Pyc \& Dunlosky, 2010; Toppino et al., 2009; Toppino \& Cohen, 2010).

In principle, choosing a short spacing interval for some items and a long spacing interval for others is a sound strategy. In practice, it was partially effective, seeming to founder on learners' insufficient accuracy when choosing which items would require a short spacing interval to ensure successful retrieval practice. The potential benefits of a long spacing interval often were lost due to failure to retrieve successfully on the practice test. The tendency to overestimate the likelihood of remembering items and thus to choose inappropriately a long spacing interval may reflect a known stability bias affecting metacognitive judgments of memory (Koriat, Bjork, Sheffer, \& Bar, 2004; Kornell \& Bjork, 2009) in which people tend to underestimate future forgetting and, consequently, overestimate future remembering.

Another noteworthy aspect of learners' choice behavior is that those who received retrieval practice chose to engage in additional practice (rather than choosing the Done option) more often than participants in Experiment 1 for whom additional practice entailed restudying. To the extent that learners chose additional practice in an effort to enhance their learning, this finding may suggest that they believe they will not benefit from more of the same kind of practice (i.e., restudying) but will gain from another kind (i.e., retrieval practice). The finding also may suggest that, at some level, learners appreciate that retrieval practice is a more potent learning technique than restudying. Some evidence for this hypothesis was provided by Toppino et al. (2018). They found that, when items were assigned arbitrary values for subsequently being remembered, learners' tendency to choose retrieval practice without feedback rather than restudying was greater for high- than for lowvalue items.

A facet of the aforementioned stability bias also may have contributed to the reduction of further practice involving restudying. Kornell and Bjork (2009) found that learners under-predicted how much they would learn from successive study opportunities, sometimes showing virtually no expectation of memory improvement with additional practice. To the extent that the stability bias led learners to believe that restudying would have little effect on their final-test performance, they may have been more likely to forego additional practice. However, if anticipated ineffectiveness is why learners frequently opted out of restudying, they clearly viewed additional practice in the form of retrieval practice to be comparatively effective and beneficial.

Turning to the Feedback conditions, learners exhibited the identical pattern of choices for practice tests, regardless of the presence or absence of feedback or its duration. Learners behaved as if feedback were absent, and not altering their spacing strategy in the presence of feedback was a major metacognitive error. Final recall in the Feedback conditions was better after a long spacing interval, regardless of whether learners' choices had been honored or dishonored. Delving into this finding more deeply, the No-Feedback and Feedback conditions did not differ on practice-test performance or on final recall of items that were retrieved successfully on the practice tests. The source of the final-recall differences between the Feedback and No-Feedback conditions can be traced to items for which practice-test recall was unsuccessful. Whereas a failed practice test without feedback provided little benefit on the final recall test for the missed items, an unsuccessful practice test followed by feedback resulted in greatly improved final recall for the missed items. Moreover, the benefit of feedback on the final recall of these items was greater following a long than a short spacing interval and with feedback durations of $4 \mathrm{~s}$ rather than $1 \mathrm{~s}$.

Presenting the full pair as feedback is essentially a restudy opportunity. When learners chose how to space restudy opportunities in Experiment 1, they consistently preferred a longer spacing interval. The same strategy would have served learners well when they encountered practice tests with feedback. It might be an even more compelling strategy with practice tests to the extent that taking a practice test can potentiate learning from a subsequent study opportunity (e.g., Arnold \& McDermott, 2013; Izawa, 1966). However, when making choices, participants seemed to ignore the potential for any learning from feedback, much less for potentiated learning. This occurred even though our participants clearly learned from feedback after unsuccessful practice tests. 
As noted earlier, other investigations also have obtained limited effects of practice-test feedback on learners' study choices (e.g., Kornell \& Son, 2009; Toppino et al., 2018; Tullis et al., 2018). Perhaps learners simply do not construe feedback to be a study opportunity. In surveys of the strategies people use in real-world learning situations, most learners report that they use practice testing not as a learning strategy but as a method of diagnosing their level of learning (e.g., Hartwig \& Dunlosky, 2012; Kornell \& Bjork, 2007; Wissman, Rawson, \& Pyc, 2012). To the extent that learners conceptualized feedback in the present experiments as an essential part of the diagnostic function of a practice test, they may have overlooked or greatly underestimated its effect on learning when they made spacing choices.

Learners often seem to exhibit little metacognitive awareness of the benefits of practice. They often do not recognize that learning was greater with spaced than with massed practice (e.g., Zechmeister \& Shaughnessy, 1980). Similarly, they often fail to realize that learning from retrieval practice is greater than from restudying (e.g., Roediger \& Karpicke, 2006). They claim that they rarely use retrieval practice to learn information (e.g, Kornell \& Bjork, 2007). And, under some circumstances, they exhibit stability biases that lead them to underestimate how much they will learn from practice (e.g., Kornell \& Bjork, 2009) and how much they will forget with the passage of time (e.g., Koriat, Bjork, Sheffer, \& Bar, 2004). However, when learners controlled the spacing between original learning and additional practice, they actually showed impressive sophistication in their metacognitive decisions.

In sum, when practice involved restudying, learners consistently preferred a long to a short spacing interval, a decision compatible with a long history of research showing a greater benefit from longer than shorter spacing intervals (e.g., Toppino \& Gerbier, 2014). When retrieval practice was involved, learners seemed to understand that successful retrieval on the practice test was necessary and that a shorter spacing interval increased the chances of successful retrieval. At the same time, they may have some appreciation that, if retrieval practice is successful, a long rather than a short spacing interval may be more beneficial. Learners' strategy worked reasonably well in the No-Feedback condition. They mostly benefited from choosing a short spacing interval before retrieval practice. Their primary metacognitive weakness was that they were not sufficiently accurate in selecting which items required a short spacing interval to encourage successful retrieval and which could be retrieved after a long spacing interval for an even greater benefit. Learners' most glaring metacognitive error, however, was that they seemed to completely discount feedback after practice tests as a learning opportunity. The failure to take feedback into account has been observed previously in research on metacognitive control (e.g., Toppino et al., 2018; Tullis et al., 2018), and its cause is an interesting topic for future research. Its effect in the present context, however, was that learners used an inappropriate spacing strategy. Although they did learn from the presentation of feedback after retrieval practice, they reduced the effectiveness of this learning by choosing a short spacing interval over a long spacing interval far too often.

Data Availability The data and materials for all experiments are available upon request from the first author. None of the experiments was preregistered.

\section{References}

Ariel, R., Dunlosky, J., \& Bailey, H. (2009). Agenda-based regulation of study-time allocation: When agendas override item-based monitoring. Journal of Experimental Psychology: General, 138(3), 432447. https://doi.org/10.1037/a0015928

Ariel, R., Dunlosky, J., \& Toppino, T. C. (2014). Contribution of degraded perception and insufficient encoding to decisions to mass or space study. Experimental Psychology, 61(2), 110-117. https://doi. org/10.1027/1618-3169/a000230

Arnold, K. M., \& McDermott, K. B. (2013). Test-potentiated learning: Distinguishing between direct and indirect effects of tests. Journal of Experimental Psychology: Learning, Memory, and Cognition, 39(3), 940-945. https://doi.org/10.1037/a0029199

Benjamin, A. S., \& Bird, R. D. (2006). Metacognitive control of the spacing of study repetitions. Journal of Memory and Language, 55(1), 126-137. https://doi.org/10.1016/j.jml.2006.02.003

Benjamin, A. S., Bjork, R. A., \& Schwartz, B. L. (1998). The mismeasure of memory: When retrieval fluency is misleading as a metamnemonic index. Journal of Experimental Psychology: General, 127, 55- 68. https://doi.org/10.1037/0096-3445.127.1.55

Carpenter, S. K., \& DeLosh, E. L. (2005). Application of the testing and spacing effects to name learning. Applied Cognitive Psychology, 19, 619 - 636. https://doi.org/10.1002/acp.1101

Cepeda, N. J., Pashler, H., Vul, E., Wixted, J. T., \& Rohrer, D. (2006). Distributed practice in verbal recall tasks: A review and quantitative synthesis. Psychological Bulletin, 132(3), 354-380. https://doi.org/ 10.1037/0033-2909.132.3.354

Dunlosky, J., \& Hertzog, C. (1997). Older and younger adults use a functionally identical algorithm to select items for restudy during multitrial learning. Journal of Gerontology: Psychological Sciences, 52B, 178 -186. https://doi.org/10.1093/geronb/52B.4. P178

Dunlosky, J., \& Nelson, T. O. (1994). Does the sensitivity of judgments of learning (JOLs) to the effects of various study activities depend on when the JOLs occur? Journal of Memory and Language, 33, 545-565. https://doi.org/10.1006/jmla.1994.1026

Ebbinghaus, H. E. (1964). Memory: A contribution to experimental psychology. New York, NY: Dover Publications (H. A. Ruger, C. E. Bussenius, \& E. R. Hilgard, (Original work published 1885).

Hartwig, M. K., \& Dunlosky, J. (2012). Study strategies of college students: Are self-testing and scheduling related to achievement? Psychonomic Bulletin \& Review, 19(1), 126-134. https://doi.org/ 10.3758/s13423-011-0181-y

Izawa, C. (1966). Reinforcement-test sequences in paired-associate learning. Psychological Reports, 18(3), 879-919. https://doi.org/10. 2466/pr0.1966.18.3.879

Kang, S. H., McDermott, K. B., \& Roediger, H. L., III. (2007). Test format and corrective feedback modify the effect of testing on long-term retention. European Journal of Cognitive Psychology, 19(4/5), 528-558. https://doi.org/10.1080/09541440601056620 
Koriat, A., Bjork, R. A., Sheffer, L., \& Bar, S. K. (2004). Predicting one's own forgetting: The role of experience-based and theory-based processes. Journal of Experimental Psychology: General, 133, 643656. https://doi.org/10.1037/0096-3445.133.4.643

Kornell, N., \& Bjork, R. A. (2007). The promise and perils of selfregulated study. Psychonomic Bulletin \& Review, 14(2), 219-224. https://doi.org/10.3758/BF03194055

Kornell, N., \& Bjork, R. A. (2009). A stability bias in human memory: Overestimating remembering and underestimating learning. Journal of Experimental Psychology: General, 138(4), 449-468. https://doi. org $/ 10.1037 / \mathrm{a} 0017350$

Kornell, N., \& Metcalfe, J. (2006). Study efficacy and the region of proximal learning framework. Journal of Experimental Psychology: Learning, Memory, and Cognition, 32, 609 - 622. https://doi.org/10.1037/0278-7393.32.3.609

Kornell, N., \& Son, L. K. (2009). Learners' choices and beliefs about selftesting. Memory, 17(5), 493-501. https://doi.org/10.1080/ 09658210902832915

Madigan, S. A. (1969). Intraserial repetition and coding processes in free recall. Journal of Verbal Learning and Verbal Behavior, 8(6), 828835. https://doi.org/10.1016/S0022-5371(69)80050-2

Melton, A. W. (1970). The situation with respect to the spacing of repetitions and memory. Journal of Verbal Learning and Verbal Behavior, 9(5), 596-606. https://doi.org/10.1016/S0022-5371(70) 80107-4

Metcalfe, J. (2002). Is study time allocated selectively to a region of proximal learning? Journal of Experimental Psychology: General, 131, 349 -363. https://doi.org/10.1037/0096-3445.131.3.349

Metcalfe, J., \& Kornell, N. (2005). A region of proximal learning model of study time allocation. Journal of Memory and Language, 52, 463- 477. https://doi.org/10.1016/j.jml.2004.12.001

Modigliani, V. (1976). Effects on a later recall by delaying initial recall. Journal of Experimental Psychology: Human Learning and Memory, 2(5), 609-622. https://doi.org/10.1037/0278-7393.2.5.609

Mulligan, N. W., \& Peterson, D. J. (2014). The spacing effect and metacognitive control. Journal of Experimental Psychology: Learning, Memory, and Cognition, 40, 306 -311. https://doi.org/ 10.1037/a0033866

Nelson, D. L., McEvoy, C. L., \& Schreiber, T. A. (2004). The University of South Florida free association, rhyme, and word fragment norms. Behavior Research Methods, Instruments, \& Computers, 36(3), 402-407. https://doi.org/10.3758/BF03195588

Nelson, T. O., \& Narens, L. (1990). Metamemory: A theoretical framework and new findings. The Psychology of Learning and Motivation, 26, 125-141.

Pyc, M. A., \& Dunlosky, J. (2010). Toward an understanding of students' allocation of study time: Why do they decide to mass or space their practice? Memory \& Cognition, 38(4), 431-440. https://doi.org/10. 3758/MC.38.4.431

Roediger, H. L., \& Butler, A. C. (2011). The critical role of retrieval practice in long-term retention. Trends in Cognitive Sciences, 15(1), 20-27. https://doi.org/10.1016/j.tics.2010.09.003
Roediger, H. L., \& Karpicke, J. D. (2006). The power of testing memory: Basic research and implications for educational practice. Perspectives on Psychological Science, 1(3), 181-210. https://doi. org/10.1111/j.1745-6916.2006.00012.x

Son, L. K. (2004). Spacing one's study: Evidence for a metacognitive control strategy. Journal of Experimental Psychology: Learning Memory and Cognition, 30(3), 601-604. https://doi.org/10.1037/ 0278-7393.30.3.601

Son, L. K. (2010). Metacognitive control and the spacing effect. Journal of Experimental Psychology: Learning, Memory, and Cognition, 36, 255-262. https://doi.org/10.1037/a0017892

Storm, B. C., Friedman, M. C., Murayama, K., \& Bjork, R. A. (2014). On the transfer of prior tests or study events to subsequent study. Journal of Experimental Psychology: Learning, Memory, and Cognition, 40(1), 115. https://doi.org/10.1037/a0034252

Toppino, T. C., \& Cohen, M. S. (2010). Metacognitive control and spaced practice: Clarifying what people do and why. Journal of Experimental Psychology: Learning, Memory, and Cognition, 36(6), 1480. https://doi.org/10.1037/a0020949

Toppino, T. C., Cohen, M. S., Davis, M. L., \& Moors, A. C. (2009). Metacognitive control over the distribution of practice: When is spacing preferred? Journal of Experimental Psychology: Learning, Memory, and Cognition, 35(5), 1352. https://doi.org/10.1037/ a0016371

Toppino, T. C., \& Gerbier, E. (2014). About practice: Repetition, spacing. and abstraction, The Psychology of Learning and Motivation, 60, 113-189. https://doi.org/10.1016/B978-0-12-800090-8.00004-4

Toppino, T. C., LaVan, M. H., \& Iaconelli, R. T. (2018). Metacognitive control in self-regulated learning: Conditions affecting the choice of restudying versus retrieval practice. Memory \& Cognition, 46(7), 1164-1177. https://doi.org/10.3758/s13421-018-0828-2

Tullis, J. G., Fiechter, J. L., \& Benjamin, A. S. (2018). The efficacy of learners' testing choices. Journal of Experimental Psychology: Learning, Memory, and Cognition, 44(4), 540. https://doi.org/10. 1037/xlm0000473

Whitten, W. B., \& Bjork, R. A. (1977). Learning from tests: Effects of spacing. Journal of Verbal Learning and Verbal Behavior, 16(4), 465-478. https://doi.org/10.1016/S0022-5371(77)80040-6

Wissman, K. T., Rawson, K. A., \& Pyc, M. A. (2012). How and when do students use flashcards? Memory, 20, 568-579. https://doi.org/10. $1080 / 09658211.2012 .687052$

Zechmeister, E. B., \& Shaughnessy, J. J. (1980). When you know that you know and when you think that you know but you don't. Bulletin of the Psychonomic Society, 15(1), 41-44. https://doi.org/10.3758/ BF03329756

Publisher's note Springer Nature remains neutral with regard to jurisdictional claims in published maps and institutional affiliations. 